\title{
Novedades en publicaciones médicas periódicas. El caso de las revistas de acceso gratuito (Open Journals)
}

\author{
Benjamín Moncada \\ Universidad Autónoma de San Luis Potosí, Hospital Central Dr. Ignacio Morones Prieto, San Luis Potosí, S.L.P., México
}

El desarrollo actual de la medicina y las ciencias biológicas ha conducido a su gran complejidad, inaccesibles en la totalidad de sus aspectos diagnósticos, patogénicos y terapéuticos para el médico, requiriendo fuentes de educación médica continua adecuadas y asequibles para mantenerse al día y con ello beneficiar a los pacientes a su cargo. Uno de los mejores recursos a la mano para este propósito es la presencia de las publicaciones médicas periódicas. Son muy numerosos estos elementos, la mayoría referidos a una especialidad en particular y en menor grado revistas generales. La calidad de las mismas se ha ganado a través del tiempo, existiendo incluso índices comparativos de esta calidad.

Desafortunadamente, en la última década ha ocurrido una situación que parece poner en grave riesgo la calidad de la información que puede llegar al médico: las revistas de acceso gratuito (Open journals)' ${ }^{1}$. En un decenio, han aumentado en el mundo de unas cuantas docenas a miles.

En la forma tradicional, un lector interesado en un artículo en particular debe poseer la revista en donde está el artículo, o tener acceso, por ejemplo, a una clave que le puede otorgar su institución. Si esto no existiera, entonces el objetivo lo alcanzaría al pagar cierta cantidad a la editorial para tener acceso al artículo de su interés. Por el contrario, en las revistas de acceso libre, como su nombre lo indica, el lector no está obligado a pagar cantidad alguna, pero quien paga es el autor del artículo (y no poco), lo cual en principio parece excelente y justo. El problema surge cuando se aprecia que las editoriales de las revistas de acceso libre resuelven la aceptación de su publicación en un tiempo muy breve, incluso invitando a ese autor a que envíe otros artículos dándole una fecha tope de aceptación y una fecha posterior de publicación, ambas con periodos de tiempo muy cortos. Se observa así que el deseo de esas editoriales es cantidad, y por supuesto, a mayor cuantía de propuestas, mayores ingresos a obtener por parte de ellas. ¿A dónde conduce todo esto? A una disminución en la calidad del material publicado bajo este sistema.

Algunas de las estrategias que se están utilizando para confundir al lector son, por ejemplo, dar a sus publicaciones el nombre casi idéntico al de una publicación ya existente, lo cual hace pensar al lector de que se trata de una revista formal, tradicional. Otra, pedir a un investigador que se haga cargo de la elaboración de un número próximo, por ejemplo a 4 meses de distancia, consiguiendo colaboradores para cumplir con la extensión habitual del número de la revista y ofreciendo incentivos (descuentos) para cuando estos investigadores deseen publicar algo en esa revista. También suelen utilizar índices de impacto no tradicionales, caracterizados por otorgar números altos.

En una publicación reciente ${ }^{2}$ se hace mención del problema de las revistas de acceso libre expresando una gran preocupación al respecto y haciendo un llamado a la clase médica para combatirlo, sobre todo tomando medidas colectivas. Una estrategia sería tener conocimiento colectivo en la población médica de este problema, hacer mención del mismo con frecuencia, y hacer notar el deterioro que en la educación médica en general (y en particular en la educación médica continua) se produciría si esto continuara. En este aspecto, la Academia Nacional de Medicina podría desempeñar un papel importante. También sugerir que cuando se examine el currículum de una persona para propósitos diversos, como tener un número suficiente de
Fecha de recepción: 23-03-2017

Fecha de aceptación: 26-04-2017 DOI:10.24875/GMM.M17000014
Gac Med Mex. 2017;153:518-519 Contents available at PubMed www.gacetamedicademexico.com 
publicaciones para lograr un objetivo, no tomar en cuenta las hechas en revistas de libre acceso.

Una manera de "combatir» a las revistar de acceso libre sería que las convencionales procuraran reducir al máximo posible el tiempo que tardan entre la recepción del artículo y la expresión de la decisión de publicarlo o no, porque esta espera larga, comparada con el tiempo breve o brevísimo que ofrecen las revistas de acceso libre, es un incentivo para que el autor se incline hacia estas últimas.

Recientemente se ha establecido una variante de los llamados Open journals, denominados «depredadores», en los que se acentúan las anomalías descritas ${ }^{3}$.

Hay algunas situaciones que deben tomarse en cuenta como algo que no corresponde a esos comentarios expresados y que se antojan válidas. Hay publicaciones de calidad que permiten el acceso libre a ellas, generalmente después de un tiempo de haber aparecido el número considerado. En otras ocasiones, al publicar un artículo que conlleve gráficas, la empresa ofrece la opción de publicarlas a color, pero con un costo por ese motivo; el autor tiene la opción de escoger blanco y negro o color, y en este último caso pagar.

\section{Bibliografía}

1. Butler D. Investigating journals: The dark side of publishing. Nature. 2013;495:433-5

2. Moher D, Moher E. Stop predatory publishers now: act collaboratively. Ann Intern Med. 2016;164:616-7.

3. Shamseer L, Moher D, Madueke O, et al. Potential predatory and legitimate biomedical journals: can tell you the difference? A cross sectional comparison. BMC. 2007;15:28. 